\title{
DOIS EXEMPLOS DE LEITURAS ESCOLARES: A CONFIGURAÇÃO DE DIFERENTES LETRAMENTOS
}

\section{TWO EXAMPLES OF SCHOOL READINGS: DIFFERENT SETUP LITERACIES}

\section{Ludovico Omar Bernardi*}

UEM

Resumo: Este artigo tem por foco a análise de uma atividade de letramento literário proposta durante o $2^{\circ}$ semestre de 2012 junto a cinco turmas do primeiro período do curso de Direito de uma Instituição de Ensino Superior privada brasileira. A atividade, por sua vez, deu-se através de um júri simulado da protagonista do romance Natália, publicado em 2010 pelo escritor português Helder Macedo. Dentre os objetivos centrais propostos e alcançados nos trabalhos, destacam-se: i) romper com o modelo autônomo (STREET, 1984), permitindo às classes a retomada do agenciamento da atividade de leitura; ii) suscitar leitores autorizados a incitar a construção de suas histórias a partir da leitura de uma obra literária, em consonância com a proposição de "letramentoS” de Rojo (2009). Isto é, com Natália no banco dos réus, as classes experienciaram o abandono da leitura artificial escolar, com vistas apenas à preparação para um exame de acesso ao ensino superior, assumindo em cada passo do processo da lide jurídica uma postura de desenvolvimento de uma leitura crítica, conforme preconizam teóricos como Abreu (2006), Aguiar (2000), Certeau (1994), dentre outros .

Palavras-Chave: Leitura. Letramentos. Letramento Literário.

Abstract: This article is focused on a literary literacy activity proposed during the 2nd half of 2012 to five classes of the first period of Law degree from an institution of Brazilian Private Higher Education. This was made through a simulated jury of the protagonist of the romance Natalia, published in 2010 by the Portuguese novelist Helder Macedo. Among the proposed and achieved core objectives of the workare: i) breaking the stand-alone model (Street, 1984), allowing classes to recover the agency of reading activity; ii) give place to authorized readers to incite the construction of their stories from the reading of a literary work according to the proposal of Rojo (2009) "literacies". That is, with Natalia in the dock, the classes experienced an alternative to the school artificial reading, that aims only to prepare for an examination of access to higher education, taking in every step of the legal deal process a development posture of a critical reading, as advocated theoreticians as Abreu (2006), Aguiar (2000), Certeau (1984), among others.

Keywords: Reading. Literacies. Literary Literacie.

\author{
${ }^{*}$ Doutor em Letras \\ pela Universidade \\ Estadual de Maringá \\ - UEM. E-mail: \\ profeludo@yahoo. \\ com.br
}




\section{Introdução}

Este estudo tem por foco uma atividade de letramento literário proposta durante o $2^{\circ}$ semestre de 2012, junto a cinco turmas do primeiro período do curso de Direito de uma Instituição de Ensino Superior privada brasileira, a qual levou ao banco dos réus ao protagonista do romance Natália, do ensaísta, poeta e romancista português Helder Macedo, publicado no Brasil em 2010.

Com relação à escolha da obra para o júri simulado, esta se justifica- em função de ser o texto uma espécie de compêndio psicanalítico e ao mesmo tempo literário, fato que favoreceu a opção por uma leitura memorialística, já que quem narra é a personagem homônima ao título do livro, em forma de diário íntimo, no ínterim 2000 a 2003, tratando-se de uma espécie de treino de escrita, um possível romance que ela própria, Natália, pudesse um dia vir a escrever, mas que, no nível do narrado, nunca se concretiza.

Dentre os objetivos que nortearam todos os trabalhos com as classes, destacam-se: i) vencer a premissa de que o que quase todos aprendem na escola é o que devem dizer sobre determinados autores e livros, conforme Abreu (2006); ii) exercitar, lembrando Eco (2003), a fidelidade e o respeito à fábula literária quando de sua interpretação; iii) dar um tratamento específico ao romance Natália, um preparo especial, haja vista o fato de a leitura de um texto literário não ser natural, retomando Aguiar (2000), com vistas a permitir que os grupos percorram todo o roteiro de fingimento que Helder Macedo traçou quando da elaboração da obra; iv) romper com o modelo autônomo, permitindo às classes a retomada do agenciamento da atividade de leitura; v) suscitar leitores autorizados a incitar a construção de suas histórias a partir da leitura de uma obra literária, em consonância com a proposição de "letramentoS” de Rojo (2009).

Ressalta-se que na segunda semana de aula do semestre cada uma das cinco turmas, com uma média de quarenta discentes cada, foi dividida em equipes: i) os promotores, responsáveis pela acusação; ii) os advogados de defesa, incumbidos de convencer os jurados da inocência da ré; iii) o júri (em número ímpar), que voto a voto argumentou sua decisão; iv) as personagens do romance que, vividas pelos discentes, deram seus testemunhos, inclusive a própria Natália; v) o juiz, experienciado pelo professor, com vistas a mediar a disputa ou lide entre os grupos durante o júri. Justificativa: em função de se tratar de um júri popular encenado, o veredito do embate não está nas mãos do magistrado, mas sim com os jurados, os quais tiveram que enunciar individualmente seus votos, sempre os argumentando.

A título de duração, a atividade de letramento literário com as turmas cumpriu dezoito semanas, tendo se iniciado logo na terceira semana de aulas do semestre e se findado na penúltima. 


\section{Da definição de letramento e suas implicações}

O surgimento do conceito de letramento advém do final do século XIX, quando da percepção de que pessoas alfabetizadas não necessariamente adquiriam competência para o uso da leitura e da escrita, não estando estas, por conseguinte, aptas para se envolver com práticas sociais de escrita. Nesse sentido, o termo surge, para Soares (2001), não para definir um conjunto de habilidades individuais, mas "o conjunto de práticas sociais ligadas à leitura e à escrita em que os indivíduos se envolvem em seu contexto social” (apud JUNG, 2003, p. 58).

Por sua vez, Kleiman (1995, apud ROJO, 2009) justifica o início de uso do conceito de letramento pela academia como uma espécie de tentativa de separação dos estudos sobre o impacto da escrita das pesquisas sobre a alfabetização, cujas conotações escolares enfatizam as competências individuais no uso e na prática da escrita. Isso porque, para a pesquisadora, a escola negligencia o letramento como prática social, preocupando-se com apenas um tipo de prática: a alfabetização, o processo de aquisição de códigos - alfabético, numérico.

Rojo (2009, p. 98), por sua vez, insiste na distinção entre os dois termos, evidenciando o foco individual do alfabetismo, "ditado pelas capacidades e competências (cognitivas e linguísticas) escolares e valorizadas de leitura e escrita (letramentos escolares e acadêmicos), numa perspectiva psicológica", em contraposição ao letramento, que visa "recobrir os usos e práticas sociais de linguagem que envolvem a escrita de uma ou de outra maneira, sejam eles valorizados ou não valorizados, recobrindo contextos sociais diversos, numa perspectiva sociológica, antropológica e sociocultural”.

Estas proposições, por sua vez, aparecem trabalhadas em Street (1984, apud ROJO, 2009), para quem, a princípio, a escola, em função do contato do indivíduo com a leitura e a escrita, e da própria natureza da escrita, fez com que o sujeito aprendesse gradativamente habilidades que o levaram a níveis evoluídos de alfabetismo. Depois, em contraposição a essa forma, definiu que as práticas de letramento indissociavelmente estão ligadas às estruturas culturais e de poder da sociedade, reconhecendo, nesse aspecto, a variedade de práticas culturais associadas à leitura e à escrita em diferentes contextos. Em outras palavras, Street (1984) propõe dois modelos de letramento nos estudos: i) o modelo autônomo, "cujas consequências para a sociedade e a cognição são derivadas de sua natureza intrínseca”; e II) o modelo ideológico, o qual "varia através dos tempos e das culturas e dentro de uma mesma cultura” (apud ROJO, 2009, p. 99), que, nas palavras de Jung (2003, p. 59), “equivale a dizer que os significados específicos que a escrita assume para um grupo social dependem dos contextos em que ela é adquirida e praticada”, sendo, portanto, as práticas de letramento aspectos da cultura e das estruturas de poder. 
Hodiernamente, todas as abordagens do letramento têm apontado para o que Rojo (2009) chama de heterogeneidade das práticas sociais de leitura, escrita e uso da língua/linguagem, reiterando o caráter sociocultural e situado de suas práticas. Nas palavras de Street (2003, apud ROJO, 2009, p. 102):

Esta posição implica o reconhecimento dos múltiplos letramentos, que variam no tempo e no espaço, mas que são também contestados nas relações de poder. Assim, os NLS não pressupõem coisa alguma garantida em relação aos letramentos e às práticas sociais com que se associam, problematizando aquilo que conta como letramento em qualquer tempo-espaço e interrogando-se sobre "quais letramentos" são dominantes e quais são marginalizados ou de resistência [ênfase adicionada por Rojo, 2009].

Ter-se-ia, assim, segundo Hamilton (2002 apud ROJO, 2009), os letramentos institucionalizados, que equivalem, para a autora, aos dominantes, haja vista estarem ligados a organizações formais similares à escola, como igreja, local de trabalho, sistema legal, estando neles previstos agentes, ou seja, professores ou pesquisadores, empresários, pastores ou padres, operadores do direito ou burocratas, que em relação ao conhecimento notabilizam-se legal e culturalmente, fazendo-se poderosos na exata proporção do poder de suas instituições. Por outro lado, ainda para Hamilton (2002 apud ROJO, 2009), há os letramentos autogerados, os quais equivalem aos marginalizados, já que não estão submetidos a regulação, controle ou sistematização por instituições ou organizações sociais, tendo justificadas suas origens nas culturas locais, na vida cotidiana e, por conseguinte, na desvalorização ou desprezo da cultura oficial. Nesse movimento, reitera Rojo (2009, p. 102) “o conceito de letramento passa a ser plural: letramentoS” [grifo da autora], não podendo haver categorias independentes, mas sim associação delas.

No que tange às implicações do letramento para o ensino escolar, Jung (2003) destaca que a escola não pode ser vista como o único lugar onde se aprende ou que apenas as crianças aprendem. Isso porque se trata de um domínio social em que alunos e professores desempenham papeis sociais distintos, os quais exigem determinados tipos de letramento. Nesse sentido, para a autora, “qualquer evento de letramento envolve aprendizagem” (JUNG, 2003, p. 66), e, em função de a escola adotar o critério de competência comunicativa como sinônimo de competência cognitiva, acaba por excluir sujeitos originários de culturas diferentes da dominante ou mesmo da valorizada por ela.

Jung (2003) também se opõe ao modelo unilinear de aquisição da leitura e da escrita adotado pela escola, em função de este oportunizar a continuidade do desenvolvimento linguístico e a aquisição do letramento escolar de crianças socializadas por grupos majoritários. Além disso, segundo a autora, esse mesmo molde se mostra excludente com crianças que não foram familiarizadas com a escrita ulteriormente a seu ingresso no 
ambiente escolar, ou ainda para com aqueles indivíduos que viveram processos diferenciados de socialização em suas comunidades de origem. Nessa perspectiva, para Jung (2003), há que se vencer na sociedade as implicações do mito do letramento, o qual foi definido por Signorini (1994 apud JUNG, 2003), como uma crença nos poderes do letramento como conhecimento das letras, como tecnologia neutra, disponível ao desejo individual de sucesso e, ao mesmo tempo, ao desejo coletivo do progresso e desenvolvimento, se considerada a esfera pública. Isso porque, de acordo com Jung (2003), dessa forma a escrita não mais se manteria como portadora da verdade absoluta e, por conseguinte, as atividades de sala de aula se veriam obrigadas a romper com o caráter exclusivamente explicativo, uma vez que o significado não mais residiria apenas no texto.

Em outras palavras, para Jung (2003), dessa forma se romperia com o molde de ensino da escrita penalizante via reforço, reprovação ou mesmo evasão escolar para aqueles que dela não se apropriaram, de modo que não mais seria justificada qualquer condição social pelo fato de as pessoas não terem aprendido a ler ou a escrever na escola ou por falta de oportunidade de frequentá-la. Isso porque no modelo teórico autônomo de letramento a escola desconsidera a realidade do grupo com o qual trabalha, sendo este incompatível com seu público, ao passo que para Terzi (1995 apud JUNG, 2003, p. 69):

O texto é visto por elas [crianças] como um conjunto de palavras cujo significado não interessa, a leitura é vista como apenas decodificação dessas palavras, e compreender o texto nada mais é que usar a estratégia de pareamento e mecanicamente localizar a resposta.

Ainda para Jung (2003) é preciso considerar que os indivíduos adquirem diferentes letramentos, e o letramento escolar deve ser visto como apenas mais um e não como o letramento, que tem destituído de poder quem não o adquire.

\section{A necessidade de se fazer letramento literário na escola}

A escola pode ser entendida como o locus onde circulam muitos textos, dentre os quais alguns passam a ter notoriedade artística. Nesse sentido, Aguiar (2000) destaca que em se tratando da leitura do texto literário, ela precisa ser aprendida pelo leitor, não lhe sendo natural, já que exige dele percorrer todo o roteiro de fingimento que o próprio autor construiu quando de sua elaboração. Em outras palavras, para Aguiar (2000), trata-se, a leitura literária, de uma leitura restrita:

É a visão de que a obra de arte - a literária, aqui no caso - se constitui num objeto único, diferente de todos os demais, que pode espelhar o mundo em volta mas dele se distingue radicalmente. Merece, portanto, um tratamento específico, um preparo especial para ser apreciado. (AGUIAR, 2000, p. 20). 
Nesse sentido, mediante a manutenção do modelo autônomo de letramento no espaço escolar, pode-se afirmar, conforme Abreu (2006), que o que quase todos aprendem na escola é o que devem dizer sobre determinados autores e livros, já que o trabalho nas classes se resume a ensinar a ler e a gostar do texto literário, decorrendo dessas práticas o fato de alguns alunos até aprenderem e tornarem-se leitores literários. Ainda para Abreu (2006, p. 39), “a literatura pode ser (ou não ser) muita coisa, mas jamais será simplesmente”. Isso porque, por trás de sua definição, reside um ato de seleção e exclusão, na maior parte das vezes sem quaisquer critérios estéticos ou linguísticos, cujo objetivo se restringe simplesmente em separar alguns textos escritos por alguns autores do conjunto dos demais textos em circulação. Por conseguinte, no modelo autônomo em vigor, para Abreu (2006, p. 40), “o que torna um texto literário não são suas características internas, e sim o espaço que lhe é destinado pela crítica e, sobretudo, pela escola no conjunto dos bens simbólicos”.

Nesta perspectiva, conforme afirma Abreu (2006), assiste-se, em especial a partir da introdução da literatura como disciplina escolar, à naturalização de seu conceito, ou seja, à sua tomada como natural e não como histórica e cultural, transformando-a em um bem comum ao ser humano, a qual deve ser lida por todos e da mesma maneira:

Apresenta-se a Literatura como algo universal, como se sempre e em todo lugar tivesse havido literatura, como se ela fosse própria ao ser humano. Um médico não precisa discutir o que é um fígado ou o que é um coração pois eles têm existência física no mundo concreto. Nós temos que discutir o que é literatura, pois ela é um fenômeno cultural e histórico e, portanto, passível de receber diferentes definições em diferentes épocas e por diferentes grupos sociais. (ABREU, 2006, p. 41).

Há que se considerar que a apreciação estética é dependente da inserção cultural dos sujeitos, sendo falaciosa qualquer concepção universalista. Para Abreu (2006), aliás, uma mesma obra pode ser lida, avaliada e investida de significações variadas por distintos grupos culturais, sendo, na maior parte das vezes, utilizado o gosto estético erudito para avaliar o conjunto de produções, decidindo-se arbitrariamente o que merece ser literatura e o que deve ser apenas trivial, popular ou comercial. Logo, a avaliação de uma obra não pode se resumir à percepção da excelência do texto, através da manutenção da concepção de uma imanente literariedade. Isso porque, conforme Abreu (2006, p. 99):

Ler um livro não é apenas decifrar letra após letra, palavra após palavra. Ler um livro é cotejá-lo com nossas convicções sobre tendências literárias, sobre paradigmas estéticos e sobre valores culturais. É sentir o peso da posição do autor no campo literário (sua filiação intelectual, sua condição social e étnica, suas relações políticas, etc.). É contrastá-lo com nossas 
ideias sobre ética, política e moral. É verificar o quanto ele se aproxima da imagem que fazemos do que seja literatura.

Não se pode negar, dessa forma, conforme Abreu (2006), que os critérios de avaliação do que pode ser definido como boa ou má literatura, bem como de que gêneros devem ou não ser incorporados à literatura, são variáveis conforme o tempo. Por conseguinte, não se tem uma literariedade intrínseca aos textos ou mesmo critérios de avaliação atemporais. Em outras palavras, 'somos todos diferentes’ e, nessa empreita, ainda segundo Abreu (2006), é preciso abrir mão do julgamento e da hierarquização do conjunto de textos via emprego de um critério único. Faz-se necessário compreender cada obra dentro do sistema de valores em que foi criada.

Nesse sentido, abandonando-se a concepção de avaliação de todas as composições apenas via critérios da criação erudita e autônoma, ficará evidente que haverá livros bons ou ruins para todos, já que nem todos compartilham dos mesmos critérios de julgamento, sendo então a cultura erudita entendida como um conjunto de produções realizadas por um determinado grupo cultural, e não como a Literatura. Desdobramentos: através da arte literária favorecer-se-á o encontro com a alteridade, seja de temas, de modos de expressão ou mesmo de critérios de avaliação. Em outras palavras, para Abreu (2006, p. 112), perceber-se-á que "não há obras boas e ruins em definitivo. O que há são escolhas - e o poder daqueles que as fazem. Literatura não é apenas uma questão de gosto: é uma questão política”. Isso porque nenhum povo até hoje deixou de contar suas histórias, porém, cada qual desenvolveu sua forma própria de fazê-lo, associada a uma maneira sui generis de apreciar estas mesmas produções.

Ademais, faz-se necessário pôr em causa a assimilação da leitura como uma passividade, já que nas palavras de Certeau (1994, p. 264), “ler é peregrinar por um sistema imposto (o do texto, análogo à ordem construída de uma cidade ou de um supermercado)". E como dizia Borges (apud CERTEAU, 1994, p. 264), “toda leitura modifica o seu objeto”, ao passo que "uma literatura difere de outra menos pelo texto que pela maneira como é lida”, consistindo o sistema de signos um conjunto de formas à espera de atribuição de um sentido pelo leitor:

Se portanto 'o livro é um efeito (uma construção) do leitor', deve-se considerar a operação deste último como uma espécie de lectio, produção própria do 'leitor'. Este não toma nem o lugar do autor nem um lugar de autor. Inventa nos textos outra coisa que não aquilo que era a 'intenção' deles. Destaca-os de sua origem. Combina os seus fragmentos e cria algo não sabido no espaço organizado por sua capacidade de permitir uma pluralidade indefinida de significações. (CERTEAU, 1994, p. 264).

Logo, não é só o escritor que se torna agente, este agenciamento também se estende ao leitor, já que a leitura é uma prática social e cultural. 
Nesse sentido, ainda para Certeau (1994), o texto só tem sentido graças aos seus leitores - de um jornal a Proust -, mudando com eles, ordenando-se de acordo com códigos de percepção que lhe escapam. Em outras palavras, torna-se texto apenas na relação com a exterioridade do leitor, via um imbricado jogo de faces combinadas: de um lado "a que organiza um espaço legível (uma literalidade)” (CERTEAU, 1984, p. 266); de outro, a que organiza um caminho que o leitor precisa percorrer para ler, “uma démarche necessária para a efetuação da obra (uma leitura).” (CERTEAU, 1984, p. 266).

Desse ponto de vista, o texto, oferecendo-se a uma leitura plural, rompe com o paradigma de que o sentido "literal” é o sinal e o efeito do poder social de uma elite, ao mesmo tempo em que abandona o papel de uma arma cultural. Afinal, para Certeau (1984), esta falaciosa concepção de uso do livro apenas por pessoas privilegiadas, confirmadas pela própria escola como verdadeiros intérpretes, tem transformado a leitura em uma literalidade ortodoxa, a qual reduz as outras leituras a heterodoxas ou dissidentes, muito embora sejam estas legítimas, a ponto de o texto, para Certeau (1984, p. 267), “se tornar uma reserva de caça, o pretexto de uma lei que legitima, como 'literal’, a interpretação de profissionais socialmente autorizados”. Nesse sentido, portanto, o letramento literário na escola, em consonância com a proposição de "letramentoS” de Rojo (2009), cumpre o importante papel não só de romper com o modelo autônomo e elitizante em vigor, mas também suscita leitores autorizados a incitar a construção de histórias a partir da leitura das obras. Entenda-se, aqui, leitura como uma prática histórica, social e variável.

\section{E assim se fez: o romance Natália, de Helder Macedo, no "banco dos réus"}

Com vistas a vencer a premissa de Abreu (2006), segundo a qual o que quase todos aprendem na escola é o que devem dizer sobre determinados autores e livros, já que o trabalho nas classes se resume a ensinar a ler e a gostar do texto literário, o pesquisador deste artigo embrenhou-se no planejamento e execução de uma ação de letramento literário com acadêmicos do primeiro período do curso de Direito de uma instituição de ensino superior privada brasileira, durante todo o segundo semestre de 2012. O texto literário escolhido para o estudo: o romance Natália, publicado no Brasil em 2010 pelo ensaísta, poeta e romancista Helder Macedo. E por que "o banco dos réus”? Simples, de modo a serem desenvolvidas as habilidades de leitura, interpretação, análise, comparação, síntese, argumentação, oratória e pensamento crítico, definidas, por sua vez, no plano de ensino da disciplina de Direito e Linguagem, na oportunidade ministrada pelo autor deste artigo, o romance Natália foi submetido a um júri simulado, o qual foi sistematizado pelo professor, a partir da divisão de cinco turmas, com uma média de quarenta discentes cada, em equipes: i) os promotores, responsáveis pela 
acusação; ii) os advogados de defesa, incumbidos de convencer os jurados da inocência da ré;iii) o júri (em número ímpar), que voto a voto argumentou sua decisão; iv) as personagens do romance, que vividas pelos discentes deram seus testemunhos e, no caso de Natália, além do relato do que vivera e fizera, foi obrigada a ouvir seu veredito; v) o juiz, exercido pelo professor, com vistas a mediar a lide entre os grupos no momento do júri. Vale ressaltar que, por se tratar de um júri popular encenado, o veredito do embate não está nas mãos do magistrado, mas sim com os jurados, os quais enunciaram individualmente seus votos, argumentando-os/ fundamentando-os.

Mas por que o letramento literário se fez importante para a realização do júri em questão, haja vista a simulação deste, bem como as habilidades determinadas no plano de ensino da disciplina? Através do letramento literário se permitiu o exercício obrigatório de fidelidade e de respeito na liberdade da interpretação da fábula de Helder Macedo. Retomando Aguiar (2000), é preciso considerar que, em se tratando da leitura de um texto literário, ela precisa ser aprendida pelo leitor, não lhe sendo natural, já que exige dele percorrer todo o roteiro de fingimento que o próprio autor construiu quando de sua elaboração. Logo, o que se fez com o romance do escritor português pré-júri consistiu em um tratamento específico, em um preparo especial para que Natália pudesse ser apreciada pelos discentes, já que enquanto romance ele pode espelhar o mundo em volta, mas ao mesmo tempo dele se distingue radicalmente. Lembrando Eco (2003), um texto literário não somente diz explicitamente aquilo que nunca poderá ser colocado em dúvida, mas, à diferença do mundo, assinala com soberana autoridade aquilo que nele deve ser assumido como relevante e aquilo que não se pode tomar como ponto de partida para interpretações livres.

O primeiro palmilhar da obra se deu com vistas ao entendimento da estrutura de Natália e suas implicações, já que Macedo oferece ao leitor uma espécie de compêndio psicanalítico e ao mesmo tempo literário, sendo narrado pela personagem homônima ao título do livro, em forma de diário íntimo, no ínterim 2000 a 2003. Percebeu-se, por sua vez, uma espécie de treino de escrita, definido por Natália como um possível romance que ela própria pudesse um dia vir a escrever, mas, que, no nível do narrado, nunca se concretiza.

Quanto ao enredo, tem por pano fundo o período da ditadura em Portugal e Guerra Colonial em África (década de 1970), momento histórico relevante para a compreensão de algumas questões obscuras do texto de Natália e de sua origem, sendo o desejo de escrever da narradora justificado por uma construção de duplos fantasmáticos, em que a figura do Avô morto há poucos meses se cola a de um escritor que ela entrevista para um programa de televisão, cujo tema não é outro senão o modo de escrever literatura (MACEDO, 2010, p. 15):

Se calhar por isso o Avô achava que eu devia ser escritora. $<$ Por isso>, o quê? Não entendo qual a relação mas, já que escrevi <por isso>, deixo ficar 
[...]. Mas foi por isso que me pus agora a escrever isto sem saber ainda para onde vou. Foi por causa do último escritor que entrevistei na televisão. Foi ele que me explicou que poderia escrever fingindo que não sou eu quem está a escrever. A fazer-me perceber que era disso que eu precisava para poder escrever. E, sobretudo, precisava escrever. Quase sinto remorsos por ter sido ele e não meu avô, quem tinha sido quem me ensinou tudo até então.

A organização do romance se dá em capítulos, os quais descrevem um dia, ou partes de um mesmo dia na vida de Natália, de modo que toda costura do enredo se dá à medida que a protagonista o vive, com vistas a descobrir quem efetivamente é. Sobre a protagonista-narradora pairam diversas incertezas quanto a sua origem, já que todo seu passado provém de histórias que o avô conta, não podendo ser esquecido o fato de que os pais de Natália morreram durante o exílio político, sendo ela encontrada ainda bebê pelo próprio avô, graças a uma carta de um policial que fornece seu paradeiro. Isso justifica, por exemplo, ela desconhecer o dia do seu nascimento, o qual foi convencionado, mais tarde, como sendo o dia vinte e três de dezembro. Também não sabe o nome que teria recebido dos pais, já que Natália foi-lhe atribuído pelo policial, "por ter nascido nesta Santa Quadra e não termos conhecimento de outro (nome)” (MACEDO, 2010, p. 36). Já para os avós, o nome da neta significa "o presente de Natal que ele (o avô) trouxe da moirana embrulhado numa manta de quadradinhos amarelos e encarnados” (MACEDO, 2010, p. 41). A narradora questiona se realmente é a filha dos pais que não conheceu: "Bem basta não ter tido pai e mãe que tivesse conhecido, mas de repente poder imaginar que não sou quem julgava ser mas, [...] outra filha, [...] que tivessem entregado ao Avô quando ele foi resgatar-me, isso não sei como aguentaria” (MACEDO, 2010, p. 37).

Natália, em função de todas essas dúvidas e problemas de identidade, acaba por ter dificuldade de se relacionar com as demais personagens: o marido Jorge faz-lhe se sentir usada como um corpo intermediário para que este chegasse ao avô; o amante Jorge Negromonte, artista plástico, faz-lhe se sentir reduzida a uma de suas instalações durante os encontros; Fátima Rua faz-lhe se sentir ameaçada de ter a identidade roubada, já que sua presença acaba por confundir a protagonista, que passa a não mais ter certeza sobre quem seria a verdadeira filha de seus pais.

Depois continuou, como se fosse parte da mesma afirmação de amor por mim: <Tu sabes perfeitamente que eu nunca quis ter sido a filha do meu pai, não sabes?, mas a filha do teu avô. A tua irmãzinha.> Sim, a Fátima não disse neta, disse filha, disse a minha irmãzinha. Minha irmã mas filha do meu avô. Neta como eu e filha como a minha mãe. A dizer uma coisa assim tão terrível e a sorrir muito docemente para concluir o que tinha dito: $<$ Mas deixa lá, eu agora já não me importo. Agora até gosto que tenha sido assim. Eu ter tido de ir para poder voltar. Para agora sermos uma só> (MACEDO, 2010, p. 200). 
Confunde-se ainda mais ao descobrir ter sido salva pelo assassino de seus pais, um policial cumprindo seu dever que, a depender do ponto de vista, estava fazendo o bem, pois os pais de Natália eram revolucionários que estavam planejando um ataque terrorista:

[...] se calhar o homem achava mesmo que era tudo a bem da nação. Se calhar achava mesmo que era um servidor da pátria. Como meus pais achavam que estavam a lutar por uma boa causa, a servir a pátria a sua maneira. Tal como o outro, a bem da nação. Na luta armada, o quer que isso fosse. O meu pai, que era contra a guerra, a treinar-se para a luta armada. Para matar gente porque era contra matar gente. A minha mãe grávida de mim a preparar mortes. [...] Execuções de gente repugnante, como o outro que me salvou? Mas se calhar para o outro os meus pais é que eram os repugnantes. Eram o inimigo, eram terroristas. [...] É preciso que essa seja a diferença, que haja uma diferença entre os bons e os maus, entre o bem e o mal, entre então e agora. (MACEDO, 2010, p. 77).

Enfim, Natália escreve tudo o que acontece em sua vida, como se as coisas realmente acontecessem apenas depois de escritas por ela. Por conseguinte, quanto mais sente dificuldade de saber quem é, mais penosa se torna sua escrita: "escrever alguma coisa que faça sentido é mais complicado do que eu julgava, Senhor Escritor da Entrevista” (MACEDO, 2010). Abandona seu diário sem suas respostas, vindo a relê-lo alguns anos mais tarde. Agora sim, como uma leitora, e só assim, depois de sua contribuição como receptora, a história pode fazer algum sentido para ela mesma, e o livro pode ter um fim. “Ora bem, cheguei ao fim. É claro que não vou mandar ao escritor nada disto que escrevi, como a certa altura imaginei que faria. Agora é só iluminar o texto e carregar na tecla delete.” (MACEDO, 2010, p. 247).

Na atividade em sala de aula, foram proposições de análise levantadas pelos grupos: i) não seria o diário de Natália uma forma de selar, autorreflexivamente, um pacto entre ela e os demais sujeitos envolvidos na narrativa - Paulo, Jorge Negromonte, Fátima Rua e o menino Diogo - e, ao mesmo tempo, reconciliar-se com o passado? ii) Natália não estaria nos levando a aceitar e validar suas metaescolhas, isto é, suas escolhas das próprias escolhas, já que o avô Diogo se revela sustentado pela contínua atividade dos personagens a ela diretamente ligados? iii) Não seria o diário de Natália uma falsa atividade, já que todas as suas ações corroboram impedimentos de que alguma coisa de fato aconteça, e que algo venha a mudar?

O veredito, unânime entre todas as classes participantes: Natália é culpada! As principais linhas argumentativas retiradas da leitura e análise literárias desencadeadas nos eventos de letramento literário propiciados durante o semestre do projeto foram: Natália, à medida que fala, coloniza as personagens em seu diário, fazendo os leitores validarem suas metaescolhas, isto é, suas escolhas das próprias escolhas, escolhas que afetam e mudam as coordenadas de seu escolher - i) o casamento com Paulo e a escolha em 
se mostrar recatada, ingênua na primeira relação sexual, diferindo muito da Natália que se deitara com alguns colegas no tempo da faculdade; ii) a escolha por se tornar amante do primo do marido, Jorge Negromonte, em parte justificada pela insatisfação de sua vida conjugal com Paulo, aliada ao ousado convite do artista para deitar-se na cama com ele, ainda no dia do casamento dela com Paulo, a desencadear o envolvimento em um arriscado jogo de sedução que tinha que ser; iii) a escolha por desenvolver uma relação conjugal com Fátima Rua, muito embora esta fosse mãe do filho de Paulo, seu ex-marido, além de ser filha do policial que matara seus pais e poupara sua vida, filha do mesmo homem que teria usado do avô Diogo para salvar-se e salvar a família. Ainda assim escolhe estar com Fátima, mesmo que esta chegue a lhe assustar com ações e declarações que pudessem caracterizar uma espécie de vingança para com ela, Natália, e para com o avô Diogo, em função da explicada generosidade vingativa deste em relação à filha do assassino e do ressentimento da filha do assassino em relação à crueldade generosa do avô; iv) escolha por assumir a maternidade do filho de Fátima e Paulo, reestabelecendo um casamento nada fortuito de outrora, mas que precisa novamente ser.

Por fim, em Natália a coisa não está escondida no diário, a protagonista é o próprio diário, tratando-se este de uma falsa atividade, ou seja, a narradora não age somente para mudar alguma coisa, ela age para impedir que alguma coisa aconteça, de modo que nada venha a mudar. Em outras palavras, em Natália a fraude é a própria verdade, não podendo deixar aqui de incluir no conteúdo do diário de Natália sua própria construção, já que o significado de cada ato de comunicação é também afirmar reflexivamente que ele é um ato de comunicação: “Ora bem, vou começar assim para ver no que isto vai dar. Fazendo uma espécie de diário que depois logo se vê se poderei reorganizar num livro como deve ser.” (MACEDO, 2010, p. 09). Trata-se, mais uma vez, da fraude a assumir a aparência da própria verdade, já que o diário é construído via seleção de fatos biográficos da narradora homônima ao título do livro, que mais condizem com a sua verdade. Nesse sentido, ela não narra para preservar sua memória, mas sim para se livrar do passado. Assim, Natália materializa no artefato diário a verdade de sua postura paranoica: ela é a trama destrutiva contra a qual está lutando, residindo todo esse logro na incapacidade do leitor de incluir na lista de suspeitos a própria ideia de desconfiança. Isso porque, como dito acima, não se deve esquecer de incluir no conteúdo de um ato de comunicação o próprio ato, já que o significado de cada ato é também afirmar-se reflexivamente como tal.

\section{Considerações Finais}

Dentre as benesses da experiência do júri simulado da protagonista da obra Natália, de Helder Macedo, certamente está o fato de que os acadêmicos envolvidos nos estudos não saíram deles sabedores do que dizer 
sobre o escritor português ou mesmo sobre sua literatura, vindo até mesmo a categorizá-la como grande ou pequena, como defende Aguiar (2000). O que as classes experienciaram com Natália no banco dos réus, pelo contrário, foi o abandono da leitura artificial escolar, com vistas apenas à preparação para um exame de acesso ao ensino superior, assumindo em cada passo do processo do júri uma postura de desenvolvimento de uma leitura crítica. Isso porque, através da vivência, preparação e execução do júri, rompeu-se com o modelo autônomo, permitindo a todos os discentes a retomada do agenciamento de suas atividades de leitura, confirmando Certeau (1994), no sentido de o texto ganhar sentido graças a eles, leitores, mudando com eles, ordenando-se de acordo com códigos de percepção que por vezes até lhes escapam. Retomando Abreu (2006), há que se considerar que uma mesma obra pode ser lida, avaliada e investida de significações variadas por distintos grupos culturais, não podendo a avaliação dela se resumir à percepção da excelência do texto, através da manutenção da concepção de uma imanente literariedade.

Um outro resultado evidente e extremamente valioso após o semestre de trabalho com as turmas, pautado na visão de se romper com o modelo autônomo, em consonância com a proposição de "letramentoS” da Rojo (2009): suscitou-se leitores autorizados a incitar a construção de histórias a partir da leitura de uma obra. Natália, retomando Aguiar (2000), através da construção da memória, como toda narrativa, mudou o mundo para trás, para o passado, condensando-o e transformando-o em experiência, mudando a compreensão dos fenômenos no presente e abrindo novas possibilidades para o futuro desses discentes das cinco turmas do primeiro período de Direito que, em 2012, depararam-se com a narradora Natália no banco dos réus.

\section{Referências}

ABREU, Márcia. Cultura letrada: literatura e leitura. São Paulo: Editora UNESP, 2006.

AGUIAR, Flávia. As questões da crítica literária. In: MARTINS, Maria Helena (Org.). Outras Leituras: literatura, televisão, jornalismo de arte e cultura, linguagem interagente. São Paulo: Editora Senac; Itaú Cultural, 2000. p. 19-35.

CERTEAU, Michel de. A invenção do cotidiano. Tradução de Ephraim Ferreira Alves. Petrópolis: Vozes, 1994.

ECO, Umberto. Sobre a literatura. Tradução de Eliana Aguiar. São Paulo: Record, 2003.

JUNG, Neiva M. Identidades Sociais na Escola: Gênero, Etnicidade, Língua e as Práticas de Letramento em uma Comunidade Rural Multilíngue. 
2003. 309 f. Tese (Doutorado em Letras) Instituto de Letras, Universidade Federal do Rio Grande do Sul, Porto Alegre, 2003.

KLEIMAN, Angela B. Modelos de letramento e as práticas de alfabetização na escola. In:.). Os significados do letramento: uma nova perspectiva sobre a prática social da escrita. Campinas: Mercado de Letras, 1995. p. 15-64.

MACEDO, Helder. Natália. Rio de Janeiro: Azougue Editorial, 2010.

ROJO, Roxane. Letramentos múltiplos, escola e inclusão social. São Paulo: Parábola Editorial, 2009.

STREET, B. Literacy in theory and practice. Cambridge: Cambridge University Press, 1984.

Recebido em maio/2016

Aceito em fevereiro/2017 